\title{
Lime-treated maize husks lower plasma LDL-cholesterol levels in normal and hypercholesterolaemic adult men from northern Mexico
}

\author{
Reyna Luz Vidal-Quintanar ${ }^{1}$, Reyna Luz Mendívil ${ }^{1}$, Mireya Peña ${ }^{1}$ and Maria Luz Fernandez ${ }^{2 *}$ \\ ${ }^{1}$ Departamento de Investigación y Posgrado en Alimentos, University of Sonora, Hermosillo, Sonora, Mexico \\ ${ }^{2}$ Department of Nutritional Sciences, University of Connecticut, Storrs, CT 06269, USA
}

(Received 22 May 1998 - Revised 20 October 1998 - Accepted 16 November 1998)

\begin{abstract}
Lime-treated maize husks (LTCH), a by-product of tortilla manufacturing in Mexico, have been shown to decrease plasma LDL-cholesterol levels in guinea-pigs by specific alterations in hepatic cholesterol metabolism. To determine whether LTCH would also lower plasma cholesterol levels in normal and hyperlipidaemic individuals, the fibre content of a typical diet was increased by supplementing free-living subjects in North-West Mexico with cookies containing $450 \mathrm{~g} \mathrm{LTCH} /$ $\mathrm{kg}$. Normal subjects $\left(\begin{array}{ll}n & 11\end{array}\right)$ with plasma cholesterol levels of less than $5.7 \mathrm{mmol} / \mathrm{l}$ and hypercholesterolaemic subjects ( $n$ 12) with plasma cholesterol levels higher than $5.7 \mathrm{mmol} / \mathrm{l}$ participated in the study. Plasma glucose, cholesterol, triacylglycerol, LDL-cholesterol and HDL-cholesterol concentrations, LDL: HDL values and blood pressure were determined at baseline and after 6 weeks of supplementation with LTCH. LTCH supplementation significantly lowered the plasma total cholesterol level by 11-15\% and LDL-cholesterol by $25 \%$, and improved the LDL: HDL value by $29-33 \%(P<0 \cdot 01)$ in both normal and hypercholesterolaemic subjects. HDL-cholesterol, triacylglycerol and glucose concentrations did not change. Both groups consumed equal amounts of LTCH per week; individuals showed excellent compliance and good acceptance of the product. Neither group changed their dietary habits during the time of the experiment as determined by $3 \mathrm{~d}$ dietary records at baseline and at week 6 . We conclude that LTCH supplements are suitable to increase fibre intake and reduce plasma LDL-cholesterol levels in healthy and hypercholesterolaemic subjects in this population.
\end{abstract}

Maize husks: Plasma cholesterol: Dietary fibre

Several authorized organizations have recommended that Western societies increase their dietary fibre intake to reduce plasma cholesterol concentrations and the associated risk of CHD (American Heart Association Task Force on Cholesterol Issues, 1990). In Mexico, CHD incidence has increased in the last 20 years and has become the leading cause of death in this country (Posadas-Romero et al. 1995). The population of North-West Mexico is characterized by elevated plasma cholesterol and triacylglycerol concentrations and low plasma HDL levels (Posadas Romero et al. 1995). Elevated plasma cholesterol levels, particularly LDLcholesterol concentrations, clearly increase risk of CHD (Anderson et al. 1992). Diet therapy should be the primary intervention for hypercholesterolaemia, followed by additional measures if serum cholesterol fails to respond adequately (National Cholesterol Education Program, Expert Panel on Detection, Evaluation and Treatment of High Blood Cholesterol in Adults, 1990; Jenkins et al. 1996).

Studies with cereal hulls and wholegrain flours have demonstrated that a fibre intake of $20-50 \mathrm{~g} / \mathrm{d}$ significantly lowers plasma LDL-cholesterol concentrations without affecting HDL-cholesterol levels, resulting in an improved lipoprotein profile (Anderson et al. 1990; Uusitupa et al. 1992; Vuorinen-Makkola et al. 1992; Hunninghake et al. 1994). Recent studies in animal models have demonstrated that the soluble fraction of fibre has a significant influence on plasma lipid levels by affecting lipoprotein secretion and catabolism (Mazur et al. 1990; McCall et al. 1992; Turley et al. 1994; Fernandez, 1995; Turley \& Dietschy, 1995). It has also been demonstrated that the lowering of plasma LDLcholesterol levels induced by pectin, guar gum and psyllium is a result of different mechanisms specific to each fibre, and that the level of dietary cholesterol contributes to the different metabolic responses (Fernandez, 1995). In addition, our previous study indicated that intake of lime-treated maize husks $(\mathrm{LTCH})$ resulted in a $25 \%$ reduction in plasma VLDL- and LDL-cholesterol concentrations in guinea-pigs (Vidal-Quintanar et al. 1997). A reduction in microsomal cholesterol, possibly induced by the action of LTCH in the intestinal lumen, altered the regulatory enzymes of cholesterol

\footnotetext{
Abbreviation: LTCH, lime-treated maize husk.

* Corresponding author: Dr Maria Luz Fernandez, fax +1 860486 3674, email mluzfern@canr1.cag.uconn.edu
} 
homeostasis, up-regulated hepatic LDL receptors and lowered plasma LDL levels in guinea-pigs (Vidal-Quintanar et al. 1997).

The present studies were undertaken to determine the effect and acceptability of low doses of LTCH and to evaluate its hypocholesterolaemic properties in adult men to verify the efficacy of LTCH in lowering plasma LDL-cholesterol that we observed in guinea-pigs (Vidal-Quintanar et al. 1997). Two groups of men (eleven normal and twelve hypercholesterolaemic) from a sedentary population in Hermosillo, a city located in North-West Mexico, were selected; their typical diet was supplemented with $32 \mathrm{~g}$ total fibre/d via intake of cookies containing $450 \mathrm{~g} \mathrm{LTCH} / \mathrm{kg}$, which were administered for 6 weeks.

\section{Materials and methods}

\section{Materials}

Enzymic cholesterol and triacylglycerol assay kits were purchased from Boehringer Mannheim (Indianapolis, IN, USA). Glucose kits were from Merck (Darmstadt, Germany). LTCH are a by-product of the tortilla industry in Mexico. The LTCH product for these studies was obtained from Maseca, Sociedad Anonima (Ciudad Obregón Sonora, Mexico) and had the following composition $(\mathrm{g} / \mathrm{kg}$ ): total fibre 685 (soluble fibre 50), protein 87 , fat 29 , ash 16 , carbohydrate 182 . The insoluble fibre portion was largely hemicellulose $(800 \mathrm{~g} / \mathrm{kg})$. As a result of the lime treatment, there was a concentration of $\mathrm{Ca}$ equivalent to $0.01 \mathrm{~g} / \mathrm{kg}$ in the husks. Wheat flour and other baking supplies were obtained from a local market.

\section{Subjects}

Twenty-three adult males, twelve with hypercholesterolaemia (plasma cholesterol concentrations $>5.7 \mathrm{mmol} / \mathrm{l}$ ) and eleven healthy subjects (plasma cholesterol concentrations
$<5.7 \mathrm{mmol} / \mathrm{l}$ ) based on their medical file, were recruited for this study through community cholesterol screenings and they all completed the study protocol. Subjects ranged in age from 22 to 53 years (mean 35 years), from 1.70 to $1.82 \mathrm{~m}$ in height and from 90 to $130 \%$ desirable body weight. Details are summarized in Table 1 . The majority of the subjects were sedentary as indicated by the low scores for the level of activity. Four subjects were considered heavy smokers, one from the normal group and three from the hypercholesterolaemic group. Both groups contained an equal number of individuals who consumed more than five beers $(1200 \mathrm{ml})$ per week.

Patients treated with lipid-lowering drugs, or with cardiovascular or active gastrointestinal diseases were excluded from the study. All subjects selected were interviewed to inform them of the nature of the experiment and all of them were requested to provide written informed consent. Comparisons between normal and hypercholesterolaemic patients indicate that this study was conducted with two very different populations regarding their baseline characteristics. The hypercholesterolaemic individuals were older in age $(P<0.01)$, and had higher plasma total cholesterol, LDLcholesterol, triacylglycerol and glucose concentrations $(P<$ 0.001) than those subjects defined as normal (Table 1). In addition, body weight and BMI were higher and blood pressure tended to be higher $(P=0 \cdot 06)$ in the hypercholesterolaemic group (Table 1). All these characteristics of the hypercholesterolaemic subjects suggest that these individuals might have had syndrome X or type II diabetes. However, because there was no documented clinical disease in these subjects, they were not removed from the study. The levels of activity, heights and numbers of subjects consuming moderate intakes of alcohol were similar in both groups. The number of smokers was higher in the hypercholesterolaemic group.

Subjects were followed on an ambulatory basis for 6 weeks. Subjects adhered to their usual diets and did not

Table 1. Baseline characteristics of normal (cholesterol $<5.7 \mathrm{mmol} / \mathrm{l}$ ) and hypercholesterolaemic (cholesterol $>5.7 \mathrm{mmol} / \mathrm{l}$ ) subjects

(Mean values and standard deviations)

\begin{tabular}{|c|c|c|c|c|}
\hline \multirow[b]{2}{*}{ Variable } & \multicolumn{2}{|c|}{ Normal $(n 11)$} & \multicolumn{2}{|c|}{ Hypercholesterolaemic ( $n$ 12) } \\
\hline & Mean & SD & Mean & SD \\
\hline Age (years) & $30 \cdot 2$ & $7 \cdot 6$ & $39.5^{\star *}$ & $8 \cdot 8$ \\
\hline Activity & 1.60 & 0.77 & $1.25^{\star *}$ & 0.59 \\
\hline Smokers $(n)$ & 1.0 & $(9 \%)$ & $3 \cdot 0^{\star \star}$ & $(25 \%)$ \\
\hline Alcohol consumption $\ddagger(n)$ & 9 & $(82 \%)$ & 9 & $(75 \%)$ \\
\hline Body weight $(\mathrm{kg})$ & 74.6 & 13.4 & $89 \cdot 4^{* *}$ & $16 \cdot 3$ \\
\hline BMI $\left(\mathrm{kg} / \mathrm{m}^{2}\right)$ & 24.6 & $2 \cdot 8$ & $28 \cdot 9^{\star *}$ & 4.7 \\
\hline Height (m) & 1.79 & $0 \cdot 1$ & 1.75 & $0 \cdot 1$ \\
\hline Systolic blood pressure $(\mathrm{mmHg}) \S$ & 121 & 11 & 132 & 16 \\
\hline Diastolic blood pressure $(\mathrm{mmHg})$ & 78 & 10 & 80 & 13 \\
\hline Plasma cholesterol $(\mathrm{mmol} / \mathrm{l})$ & 5.06 & 0.42 & $6 \cdot 80^{* *}$ & 0.49 \\
\hline Plasma triacylglycerols $(\mathrm{mmol} / \mathrm{l})$ & 0.66 & 0.25 & $2 \cdot 25^{\star \star}$ & 1.35 \\
\hline Plasma HDL-cholesterol (mmol/l) & 1.00 & 0.17 & $0.86^{\star *}$ & 0.27 \\
\hline Plasma glucose $(\mathrm{mmol} / \mathrm{l})$ & 4.94 & 0.13 & $5 \cdot 72^{\star *}$ & 0.11 \\
\hline
\end{tabular}

Mean values were significantly different from those for normal subjects: ${ }^{* *} P<0.01$ (unpaired $t$ test).

$\dagger 1=$ inactive, 2 = active (2-3 h exercise/week) and $3=$ very active ( $5-6 \mathrm{~h}$ exercise/week).

$¥$ More than five beers $(1200 \mathrm{ml})$ per week.

$\S$ Systolic blood pressure was almost significantly higher in hypercholesterolaemic individuals $(P=0.06)$. 
change lifestyle during the 6 weeks of the experiment. Both groups, normal and hypercholesterolaemic individuals, consumed daily 72 (SD 2) g cookies (approximately ten cookies) containing $450 \mathrm{~g} \mathrm{LTCH} / \mathrm{kg}$. Plasma lipids and other baseline variables were established after the second visit. All human experiments were carried out according to the guidelines of the University of Sonora and protocols were approved by the human subject committee.

\section{Preparation of cookies}

The LTCH-cookies were baked following the micro-method III (Finney et al. 1950) in a pilot plant twice weekly (Monday and Thursday) for 6 weeks. The chemical composition of the cookies is shown in Table 2. Individual packages containing the 72 (SD 2) g daily intake of cookies were handed to the patients on the Tuesday and Friday of every week of the study. Cookies were similar in colour, taste, texture and shape to those that are sold at Natural Food stores in the city of Hermosillo.

\section{Additional measurements}

Informed consent, a medical history and a physical examination were obtained from each subject during the grouping time (baseline period). In addition, $3 \mathrm{~d}$ diet records were obtained at baseline and during week 6 to calculate the amounts of nutrients consumed, including fat, protein, carbohydrate, dietary fibre and dietary cholesterol using a computerized nutrient database which contains typical Mexican food items (Hernandez et al. 1987). Personnel from the study visited each patient twice weekly to distribute the packages of cookies and the weekly discomfort questionnaire. To reduce possible gastrointestinal effects of increased fibre intake, subjects were advised to consume $36 \mathrm{~g}$ cookies in the morning and the other half in the evening. Body weight was recorded weekly.

\section{Plasma lipids and glucose}

Plasma lipids were measured at baseline and after 6 weeks. Standardization and quality control for plasma cholesterol and triacylglycerol assays have been maintained in our

Table 2. Chemical composition of cookies containing lime-treated maize husk*

(Mean values and standard deviations for four determinations)

\begin{tabular}{lcc}
\hline & \multicolumn{2}{c}{ Composition $(\mathrm{g} / \mathrm{kg})$} \\
\cline { 2 - 3 } Variable & Mean & $\mathrm{SD}$ \\
\hline Moisture & 89 & 1 \\
Protein & 78 & 4 \\
Fat & 240 & 14 \\
Ash & 29 & $0 \cdot 2$ \\
Total fibre & 346 & 124 \\
$\quad$ Soluble fraction & 55 & 10 \\
Insoluble fraction & 292 & 21.6 \\
Carbohydrates & 306 & 28.8 \\
\hline
\end{tabular}

${ }^{*}$ Measured using the official methods of the American Association of Cereal Chemists (1990). laboratory by participation in the Centers for Disease Control-National Lung and Blood Institute Lipid Standardization Program since 1989. Two blood samples (at baseline and after 6 weeks) were obtained to measure total plasma cholesterol, triacylglycerol and HDL-cholesterol concentrations. Total cholesterol was determined by enzymic methods (Allain et al. 1974) using Boehringer-Mannheim cholesterol standards. HDL-cholesterol was measured in the supernatant fraction after precipitation of apolipoprotein B-containing lipoproteins (Warnick et al. 1982, 1996), and LDL-cholesterol was calculated as described by Friedewald et al. (1978). Triacylglycerols were determined after adjusting for free glycerol according to the method of Carr et al. (1993). Plasma glucose was determined according to the method of Behall et al. (1984).

\section{Statistics}

Differences in dietary intake and baseline characteristics between normal and hypocholesterolaemic individuals were calculated by using an unpaired $t$ test with a statistical software program (SAS Institute Inc., Cary, NC, USA; 1988). Differences in the measured variables within treatment groups were evaluated using paired $t$ test and the same statistical program. Within-group analyses were averages of measurements obtained during the establishment of baseline, compared with average measurements obtained during the final week of the treatment period. Day-to-day variability in plasma lipid measurements were assessed by Pearson correlation coefficients and paired $t$ test to assess whether plasma lipid values obtained on day 1 were significantly different from those obtained on day 2 during baseline and at the end of the experiment.

\section{Results}

\section{Characteristics at baseline}

A record of compliance, acceptability, future intake and side-effects were kept for all individuals participating in the study. As indicated in Table 3, the individuals belonging to the normal group had overall higher compliance and acceptance of the fibre supplement and complained less of side-effects than the hypercholesterolaemic individuals. These observations suggest that for this particular study the normal individuals were more compliant and changed their dietary habits relatively easily compared with the hypercholesterolaemic group.

\section{Diets and fibre intake}

The typical northern Mexican diet followed during the treatment period (as assessed by $3 \mathrm{~d}$ dietary record at baseline and at the end of the 6 weeks) provided $53-55 \%$ total energy as carbohydrate, $19-25 \%$ energy as protein, $23-26 \%$ energy as fat, $13-16 \%$ energy as saturated fatty acids. The amount of dietary cholesterol ranged from 224 to $1819 \mathrm{mg} / \mathrm{d}$ with mean values of 529 and $865 \mathrm{mg}$ for the hypercholesterolaemic and normal groups respectively (Table 4), values that indicate high consumption of animal products. Both groups of subjects consumed similar amounts of total dietary fibre $(61-69 \mathrm{~g} / \mathrm{d})$ which is high compared with the 
Table 3. Acceptability and side-effects of cookies containing $450 \mathrm{~g}$ lime-treated maize husks $/ \mathrm{kg}$ for normal (cholesterol $<5.7 \mathrm{mmol} / \mathrm{l}$ ) and hypercholesterolaemic (cholesterol $>5.7 \mathrm{mmol} / \mathrm{l}$ ) subjects*

\begin{tabular}{lll}
\hline & \multicolumn{2}{c}{ Number of subjects in the group } \\
\cline { 2 - 3 } Variable & Normal & Hypercholesterolaemic \\
\hline Compliance: & 7 & 7 \\
$\quad$ Good & 3 & 3 \\
$\quad$ Moderate & 1 & 2 \\
$\quad$ Poor & 9 & 8 \\
Acceptability: & 2 & 4 \\
$\quad$ Easy to take & 0 & 0 \\
Difficult to take & & \\
Impossible to take & 6 & 4 \\
Future intake: & 2 & 5 \\
$\quad$ Will take it & 2 & 3 \\
$\quad$ Will perhaps take it & & \\
$\quad$ Will not take it & 5 & 3 \\
Side-effects: & 4 & 6 \\
$\quad$ No. of defecations & 3 & 5 \\
Bloated & 4 & 0 \\
Flatus & 1 & \\
Fullness & & \\
None & &
\end{tabular}

* For details of cookies, subjects and procedures, see Tables 1 and 2 and pp. 282-283.

majority of the world's population and was mainly derived from tortillas and beans (approximately $62 \%$ total fibre consumed), two typical food items in this population. There were no statistically significant differences in the consumption of nutrients between normal and hypercholesterolaemic subjects at baseline or after 6 weeks (Table 4). Diets were not significantly modified during the treatment except for the amount of fibre consumed in the form of maize husks. Both groups consumed 72 (SD 2) g cookies (32 (SD 1) g LTCH or 24 (SD 1) g total dietary fibre) along with their typical diet for 6 weeks. The amount of supplementary fibre consumed per week as LTCH, in cookies, by the two groups was not significantly different (232 (SD 7.9) v. 233
(SD 7.3) g/week). The supplement of $24 \mathrm{~g} / \mathrm{d}$ total dietary fibre contained only $4 \mathrm{~g}$ soluble fibre.

\section{Plasma lipids and other variables}

There were no significant differences in baseline serum total cholesterol, HDL-cholesterol, LDL-cholesterol or triacylglycerol concentrations between blood samples 1 and 2 . Pearson correlation coefficients between measurements varied from 0.63 to 0.95 (results not shown) indicating no significant differences in these variables between day 1 and day 2 .

At the end of the supplementation period, all measurements were analysed and compared with baseline values. Body weight and blood pressure values after week 6 of experimentation were not significantly different $(P>0.05)$ from baseline for all subjects.

Plasma total cholesterol and LDL-cholesterol levels were significantly $(P<0.01)$ lowered by $11-15 \%$ and by $24-25 \%$ respectively by LTCH supplementation in the normal and hypercholesterolaemic groups. Total plasma HDL-cholesterol, triacylglycerol and glucose concentrations were not affected by consumption of the dietary supplement (Table 5). However, LDL : HDL ratios were 29-33\% lower $(P<0.05)$ after 6 weeks of treatment with LTCH. These results indicate that supplementation of the diet with cookies containing LTCH had a beneficial effect in the plasma lipid profile in both populations, although individuals did not otherwise alter their dietary habits or change their lifestyle during the experimental period.

\section{Discussion}

In this study we have demonstrated that husks from limetreated maize given as a supplement are effective in lowering plasma LDL-cholesterol levels in normal and hypercholesterolaemic individuals even without other significant changes in their dietary patterns during the time of the experiment.

Table 4. Characteristics of the diets consumed by normal (cholesterol $<5.7 \mathrm{mmol} / \mathrm{l})$ and hypercholesterolaemic $(\mathrm{HC}$; cholesterol $>5.7 \mathrm{mmol} / \mathrm{l})$ subjects from $3 \mathrm{~d}$ records taken at baseline and after 6 weeks of supplementation with lime-treated maize husk (LTCH) cookies* (Mean values and standard deviations for eleven normal and twelve HC subjects)

\begin{tabular}{|c|c|c|c|c|c|c|c|c|}
\hline \multirow[b]{3}{*}{ Nutrient } & \multicolumn{4}{|c|}{ Baseline } & \multicolumn{4}{|c|}{6 weeks } \\
\hline & \multicolumn{2}{|c|}{ Normal } & \multicolumn{2}{|c|}{$\mathrm{HC}$} & \multicolumn{2}{|c|}{ Normal } & \multicolumn{2}{|c|}{$\mathrm{HC}$} \\
\hline & Mean & SD & Mean & SD & Mean & SD & Mean & SD \\
\hline Total energy $(\mathrm{MJ} / \mathrm{d})$ & 13.8 & $4 \cdot 0$ & $14 \cdot 6$ & 1.4 & 13.2 & 4.5 & 14.5 & 3.5 \\
\hline Protein $(\mathrm{g} / \mathrm{d})$ & 178 & 45 & 220 & 180 & 154 & 40 & 202 & 162 \\
\hline Protein (\% energy) & $20 \cdot 8$ & $5 \cdot 2$ & 24.9 & $19 \cdot 2$ & 19.5 & $5 \cdot 0$ & $23 \cdot 0$ & $18 \cdot 0$ \\
\hline Saturated fat (\% energy) & $13 \cdot 0$ & 4.0 & $14 \cdot 2$ & 4.5 & $15 \cdot 9$ & $4 \cdot 8$ & 14.6 & 5.7 \\
\hline Total carbohydrate $(\mathrm{g} / \mathrm{d})$ & 461 & 192 & 462 & 115 & 459 & 218 & 463 & 187 \\
\hline Carbohydrate (\% energy) & 54 & 22 & 52 & 23 & 55 & 27 & 53 & 21 \\
\hline Dietary cholesterol $(\mathrm{mg} / \mathrm{d})$ & 697 & 480 & 632 & 250 & 865 & 479 & 529 & 435 \\
\hline Dietary fibre $(\mathrm{g})$ & 68 & 24 & 69 & 13 & 67 & 30 & 61 & 19 \\
\hline Dietary fibre + LTCH cookie & \multicolumn{2}{|c|}{-} & \multicolumn{2}{|c|}{ - } & $100 \cdot 1$ & 30.4 & 94.8 & 18.9 \\
\hline Soluble fibre from supplement & \multicolumn{2}{|c|}{ - } & \multicolumn{2}{|c|}{ _ } & $4 \cdot 0$ & 0.8 & $4 \cdot 0$ & 0.7 \\
\hline
\end{tabular}

\footnotetext{
${ }^{*}$ For details of cookies, subjects and procedures, see Tables 1 and 2 and pp. 282-283.
} 
Table 5. Plasma variables, body weight and blood pressure of normal (cholesterol $<5.7 \mathrm{mmol} / \mathrm{l}$ ) and hypercholesterolaemic (cholesterol $>5.7 \mathrm{mmol} / \mathrm{l}$ ) men before and after 6 weeks supplementation of the diet with cookies containing lime-treated maize husk $\dagger$

(Mean values and standard deviations)

\begin{tabular}{|c|c|c|c|c|c|c|c|c|}
\hline \multirow[b]{3}{*}{ Variable } & \multicolumn{4}{|c|}{ Normal (n 11) } & \multicolumn{4}{|c|}{ Hypercholesterolaemic (n 12) } \\
\hline & \multicolumn{2}{|c|}{ Baseline } & \multicolumn{2}{|c|}{ Final } & \multicolumn{2}{|c|}{ Baseline } & \multicolumn{2}{|c|}{ Final } \\
\hline & Mean & SD & Mean & SD & Mean & SD & Mean & SD \\
\hline Total cholesterol (mmol/l) & 5.06 & 0.42 & $4 \cdot 25^{*}$ & 0.56 & $6 \cdot 80$ & 0.49 & $6.05^{*}$ & 0.58 \\
\hline HDL-cholesterol (mmol/l') & 1.00 & 0.17 & 0.99 & 0.17 & 0.86 & 0.27 & 0.93 & 0.16 \\
\hline LDL-cholesterol (mmol/l) & 3.65 & 0.41 & $2 \cdot 67^{*}$ & 0.66 & $5 \cdot 25$ & 0.91 & $3 \cdot 90^{*}$ & 0.88 \\
\hline Total cholesterol: HDL-cholesterol & $5 \cdot 4$ & $1 \cdot 3$ & $4 \cdot 2^{*}$ & 1.4 & $8 \cdot 2$ & $2 \cdot 1$ & $6 \cdot 8^{*}$ & 1.9 \\
\hline LDL-cholesterol: HDL-cholesterol & $3 \cdot 8$ & $1 \cdot 2$ & $2 \cdot 7^{*}$ & $1 \cdot 2$ & $5 \cdot \overline{7}$ & 1.9 & $3 \cdot 8^{*}$ & 1.4 \\
\hline Triacylglycerols $(\mathrm{mmol} / \mathrm{l})$ & 0.66 & 0.25 & 0.81 & 0.34 & $2 \cdot 25$ & $1 \cdot 35$ & $2 \cdot 35$ & 0.93 \\
\hline Glucose $(\mathrm{mmol} / \mathrm{l})$ & 4.90 & 0.13 & $5 \cdot 05$ & $0 \cdot 34$ & $5 \cdot 70$ & $0 \cdot 11$ & $5 \cdot 71$ & 0.11 \\
\hline Body weight (kg) & $74 \cdot 6$ & $13 \cdot 4$ & $75 \cdot 7$ & $13 \cdot 6$ & $89 \cdot 4$ & $16 \cdot 3$ & $90 \cdot 5$ & $16 \cdot 2$ \\
\hline Systolic blood pressure (mmHg) & 121 & 11 & 121 & 10 & 132 & 16 & 132 & 20 \\
\hline Diastolic blood pressure $(\mathrm{mmHg})$ & 78 & 10 & 74 & 15 & 80 & 13 & 82 & 10 \\
\hline
\end{tabular}

Mean values were significantly different from the corresponding baseline values: ${ }^{\star} P<0.05$.

†For details of cookies, subjects and procedures, see Tables 1 and 2 and pp. 282-283.

These studies confirm our preliminary findings in guineapigs, in which a $25 \%$ reduction in LDL-cholesterol was observed with intakes of 75 and $100 \mathrm{~g} \mathrm{LTCH} / \mathrm{kg}$ diet (VidalQuintanar et al. 1997). In addition, in the present study LTCH supplementation was effective in two very different populations in terms of plasma lipid profiles and other characteristics associated with increased risk of CHD. For example, the hypercholesterolaemic group had a more undesirable plasma lipid profile, higher plasma glucose level, higher weight, tended to have higher blood pressure and contained a higher percentage of smokers. It is well known that elevated plasma LDL-cholesterol concentrations, hypertriacylglycerolaemia (Shepherd \& Packard, 1996), body weight higher than optimal, smoking and hypertension are all factors greatly associated with CHD risk (American Heart Association Task Force on Cholesterol Issues, 1990). Although the total plasma cholesterol level was within the low risk range for this variable in the normal subjects (Jenkins et al. 1996), all individuals presented low plasma HDL-cholesterol levels and a high LDL : HDL value which is considered to be an independent risk factor for cardiovascular disease (Grover et al. 1995). In addition, the normal group was younger which also raises the question of whether their plasma cholesterol will increase to borderline or high risk values as they become older (Knopp et al. 1981).

Plasma triacylglycerol and HDL-cholesterol concentrations were not affected by LTCH, in common with most reported clinical studies on the effects of fibre on plasma lipids (Bell et al. 1989; Anderson et al. 1990; Everson et al. 1992; Jenkins et al. 1996). Interestingly, there was a trend (non-significant) for higher plasma triacylglycerols and VLDL-cholesterol (calculated by dividing plasma triacylglycerols by five; Friedwald et al. 1978) after LTCH intake in both the normal and the hypercholesterolaemic subjects. Einarsson et al. (1991) reported that hyperlipidaemic patients had lower cholesterol levels but higher triacylglycerol levels after treatment with the bile acid-binding resin cholestyramine. These observations can be explained as a result of the liver trying to maintain homeostasis. Since cholestyramine accelerates the removal of plasma LDLcholesterol by up-regulating LDL receptors, the liver also produces more VLDL as a compensatory mechanism. As VLDL is the major carrier of triacylglycerols in plasma, it is not surprising that plasma triacylglycerol levels were increased (Einarsson et al. 1991). Results from the present study suggest that a similar mechanism may take place in response to LTCH intake, although there was only a slight increase in triacylglycerol level which was not significant.

\section{Dietary patterns of the Mexican population and effects of lime-treated maize husks}

When trying to analyse the effects of LTCH in this particular population, an important point to consider is that the individuals who participated in this study consumed diets high in saturated fat (14-17\% dietary energy) which may account for the high concentrations of dietary cholesterol $(529-865 \mathrm{mg} / \mathrm{d})$ derived mostly from meat, organ meats and eggs; however, and in contradiction to this specific dietary habit, their diets were also characterized by relatively high amounts of dietary fibre which were possibly three times higher than in industrialized countries where there is the concept of a 'fibre-depleted diet' (Spiller, 1994). Interestingly, in our study nutrient and energy intakes were similar whether the subjects were classified as normal or hypercholesterolaemic, suggesting that other factors in addition to dietary pattern contribute to the elevated plasma cholesterol and triacylglycerol levels observed in the hypercholesterolaemic individuals.

This diet is typical of the state of Sonora where meat products, beans and tortillas are considered staples for that socio-economic group of the population (Wyatt et al. 1995). In a study where the diets of a sample of 505 subjects from that region in Mexico were analysed, there was an average consumption of $329 \mathrm{~g}$ beans/d and $358 \mathrm{~g}$ tortillas/d, which mimics the diet reported by our subjects in the present study. The daily consumption values $(\mathrm{g} / \mathrm{d})$ of dietary fat and protein 
reported by Wyatt et al. (1995) were similar to the average intakes of those nutrients in the present study for all our subjects, although the amount of dietary fibre was somewhat higher $(49.2 v .61 \mathrm{~g})$ in the present study.

Significant reductions in plasma LDL-cholesterol and in the LDL: HDL value were observed with no other changes in dietary habits, a situation which verifies the importance of using LTCH as an additional aide to a Step I diet (American Heart Association Task Force on Cholesterol Issues, 1990). Soluble fibre, when given as an adjunct to a prudent diet (Bell et al. 1989; Anderson et al. 1992) or in combination with a low-saturated-fat diet (Sprecher et al. 1993) has been shown to be equally effective in reducing plasma LDLcholesterol levels and improving the plasma lipoprotein profile. These results emphasize the importance of the use of fibre supplements to improve plasma lipid levels in addition to significant modifications in dietary patterns and lifestyle and not as the only resource. Thus, it is of particular interest to determine the effectiveness of LTCH in decreasing plasma cholesterol concentrations when important modifications have been made to the dietary patterns.

\section{Possible mechanisms of action of lime-treated maize husks}

The significant reductions in total cholesterol, LDL-cholesterol and LDL : HDL value obtained by LTCH consumption was similar to or greater than those reported in normal or in hypercholesterolaemic individuals consuming psyllium (Everson et al. 1992; Davidson et al. 1996), subjects taking guar gum (Bosello et al. 1984; Landin et al. 1992), pectin (Judd \& Truswell, 1982), oat bran (Kirby et al. 1981; Lia et al. 1995) or other sources of fibre including beans (Anderson \& Gustafson, 1988) and cereals (Bell et al. 1989). In contrast to all these studies, subjects consuming LTCH had only an additional $4 \mathrm{~g}$ soluble fibre/d. LTCH contains only $50 \mathrm{~g}$ soluble fibre $/ \mathrm{kg}$ and supplementation of the diet with this material resulted in hypercholesterolaemic responses comparable with those to fibres containing a much higher proportion of soluble fibre (Kirby et al. 1981; Judd \& Truswell, 1982; Anderson \& Gustafson, 1988; Everson et al. 1992; Landin et al. 1992; Davidson et al. 1996).

In our previous report on the effect of LTCH in guineapigs, we observed a significant reduction in hepatic microsomal cholesterol by intake of 75 or $100 \mathrm{~g} \mathrm{LTCH} / \mathrm{kg}$ diet. These decreases in that particular pool of hepatic cholesterol were associated with significant modifications in hepatic cholesterol metabolism by alterations in some of the regulatory enzymes that maintain hepatic cholesterol homeostasis. Hydroxymethylglutaryl-CoA reductase (EC 1.1.1.34) and cholesterol $7 \alpha$-hydroxylase ( $E C$ 1.14.13.17) activities were up-regulated while hepatic acetyl CoA:cholesterol acyl transferase (EC 2.3.1.26) was down-regulated in guineapigs consuming LTCH. These responses are similar to those observed in guinea-pigs by consuming other sources of soluble dietary fibre (Fernandez, 1995) and are related to the action of fibre, or in this case of LTCH, in the intestinal lumen. It is possible that human subjects also presented alterations in hepatic cholesterol metabolism as a response to LTCH since the magnitude of plasma LDL-cholesterol lowering was similar to that seen in guinea-pigs.
LTCH might have a comparable model of action in man as has been reported for sources of soluble dietary fibre (Anderson, 1987; Schneeman \& Tinker, 1995), namely (1) interruption of the enterohepatic circulation of bile acids which would increase the demand for hepatic cholesterol for bile acid synthesis, or (2) decreases in cholesterol absorption associated with reduced delivery of cholesterol to the liver through chylomicron remnants (Fernandez, 1995). Either of these two mechanisms would result in a reduction in hepatic cholesterol and, thus, in modification of the secretion rate of VLDL and of LDL turnover (Dietschy et al. 1993). In guinea-pigs the decreases in hepatic cholesterol induced by sources of soluble dietary fibre are associated with decreased rates of apolipoprotein B secretion, decreased conversion of VLDL to LDL and increased LDL fractional catabolic rate (Fernandez, 1995; Fernandez et al. 1997). In the particular case of $\mathrm{LTCH}$, we have observed an up-regulation of hepatic apolipoprotein $\mathrm{B} / \mathrm{E}$ receptors which can be related to increased LDL catabolism and decreases in plasma LDL-cholesterol (Vidal-Quintanar et al. 1997).

From these studies we conclude that LTCH significantly lowers plasma LDL-cholesterol in normal and hypercholesterolaemic adult males in the same order of magnitude as other typical sources of fibre containing higher proportions of soluble fibre. Based on our studies in guinea-pigs and on the observations in the present study, it is possible that LTCH might have a similar mode of action in the intestinal lumen to that of other better known, more studied sources of soluble fibre, which would explain the comparable plasma LDL lowering achieved by LTCH when compared with other typical soluble fibres.

\section{References}

Allain CC, Poon LS, Richmond W \& Fu PC (1974) Enzymatic determination of total serum cholesterol. Clinical Chemistry 20, 470-475.

American Association of Cereal Chemists (1900) Approved methods of the American Association of Cereal Chemists. St Paul, MN: AACC.

American Heart Association Task Force on Cholesterol Issues (1990) The cholesterol facts: a summary of the evidence relating dietary fats, serum cholesterol, and coronary heart disease. Circulation 81, 1721-1733.

Anderson JW (1987) Dietary fiber, lipids and atherosclerosis. American Journal of Cardiology 60, 17G-22G.

Anderson JW \& Gustafson NJ (1988) Hypocholesterolemic effect of oat and bean products. American Journal of Clinical Nutrition 48, 749-753.

Anderson JW, Riddell-Mason S, Gustafson NJ, Smith SF \& Mackey M (1992) Cholesterol-lowering effects of psylliumenriched cereal as an adjunct to a prudent diet in the treatment of mild to moderate hypercholesterolemia. American Journal of Clinical Nutrition 56, 93-98.

Anderson JW, Spencer DB, Hamilton CC, Smith SF, Tietyen J, Bryant CA \& Oeltgen P (1990) Oat-bran cereal lowers serum total and LDL cholesterol in hypercholesterolemic men. American Journal of Clinical Nutrition 52, 495-499.

Behall KM, Schofield DJ, Lee KH \& Moser PB (1984) Blood glucose and hormone levels in adult males fed four refined fibers. Nutrition Reports International 30, 537-543.

Bell LP, Hectome K, Reynolds H, Balm TK \& Hunninghake DB (1989) Cholesterol-lowering effects of soluble-fibre cereals as 
part of a prudent diet for patients with mild to moderate hypercholesterolemia. Journal of the American Medical Association 261, 3419-3423.

Bosello O, Cominacini L, Zocca I, Garbin U, Ferrari F \& Davoli A (1984) Effects of guar gum on plasma lipoproteins and apolipoproteins C-II and C-III in patients affected with familial combined hyperlipoproteinemia. American Journal of Clinical Nutrition 40, 1165-1174.

Carr T, Andresen CJ \& Rudel LL (1993) Enzymatic determination of triglyceride, free cholesterol and total cholesterol in tissue lipid extracts. Clinical Biochemistry 26, 39-42.

Davidson MH, Dugan LD, Burns JH, Sugimoto D, Story K \& Drennan K (1996) A psyllium-enriched cereal for the treatment of hypercholesterolemia in children: a controlled double-blind, crossover study. American Journal of Clinical Nutrition 63, 96102.

Dietschy JM, Turley SD \& Spady DK (1993) Role of liver in the maintenance of cholesterol and low density lipoprotein homeostasis in different animal species, including humans. Journal of Lipid Research 34, 1637-1659.

Einarsson K, Ericsson S, Ewerth S, Reihner E, Rudling M, Stahlberg D \& Angelin B (1991) Effects of cholestyramine on plasma triglyceride concentrations in moderate hyperlipidaemic patients. European Journal of Clinical Pharmacology 40, S53S68.

Everson GT, Daggy BP, McKinley C \& Story J (1992) Effects of psyllium hydrophilic mucilloid on LDL-cholesterol and bile acid synthesis in hypercholestolemic men. Journal of Lipid Research 23, 1183-1192.

Fernandez ML (1995) Distinct mechanisms of plasma LDL lowering by dietary fiber in the guinea pig: specific effects of pectin, guar gum, and psyllium. Journal of Lipid Research 36, 23942404.

Fernandez ML, Vergara-Jimenez M, Conde K, Behr T \& AbdelFattah G (1997) Regulation of apolipoprotein B-containing lipoproteins by dietary soluble fiber in guinea pigs. American Journal of Clinical Nutrition 65, 814-822.

Finney KF, Morris VH \& Yamazaki WT (1950) Micro versus macro cookies baking procedures for evaluating the cookie quality of wheat varieties. Cereal Chemistry 27, 42-44.

Friedewald WT, Levy RI \& Fredrickson DS (1978) Estimation of the concentration of low-density lipoprotein cholesterol in plasma, without use of the preparative ultracentrifuge. Clinical Chemistry 18, 499-502.

Grover SA, Coupal L \& Hu X-P (1995) Identifying adults at increased risk of coronary heart disease. How well do the current cholesterol guidelines work? Journal of the American Medical Association 274, 4801-4806.

Hernandez M, Chavez A \& Bourges H (1987) Nutritional Value of Mexican Foods, 10th ed. Mexico City: Publicaciones del Instituto Nacional de La Nutricion.

Hunninghake DB, Miller VT, LaRosa JC, Kinosian B, Brown V, Howard WJ, SiDerio FJ \& O'Connor RR (1994) Hypocholesterolemic effects of a dietary fiber supplement. American Journal of Clinical Nutrition 59, 1050-1054.

Jenkins DJA, Spadofora PJ \& Jenkins AL (1996) Effect of dietary fiber on plasma lipoproteins. In Handbook of Lipids in Human Nutrition, pp. 173-198 [GA Spiller, editor]. Boca Raton, FL: CRC Press Inc.

Judd PA \& Truswell AS (1982) Comparison of the effects of highand low-methoxy pectins on blood and faecal lipids in man. British Journal of Nutrition 48, 451-458.

Kirby RW, Anderson JW, Sieling B, Rees ED, Lin Chen W-J, Miller RE \& Kay RM (1981) Oat-bran intake selectively lowers serum low-density lipoprotein cholesterol concentrations of hypercholesterolemic men. American Journal of Clinical Nutrition 34, 824-829.
Knopp RH, Warnick GR \& Walden CE (1981) Relationship of gender, sex hormone use and age with lipoprotein cholesterol. Atherosclerosis 39, 133-138.

Landin K, Holm G, Tengborn L \& Smith U (1992) Guar gum improves insulin sensitivity, blood lipids, blood pressure and fibrinolysis in healthy men. American Journal of Clinical Nutrition 56, 1061-1065.

Lia A, Hallmans G, Sandberg A-S, Sundberg B, Aman P \& Andersson H (1995) Oat $\beta$-glucan increases bile acid excretion and a fiber-rich barley fraction increases cholesterol excretion in ileostomy subjects. American Journal of Clinical Nutrition 62, 1245-1251.

McCall MR, Mehta T, Leathers CW \& Foster DM (1992) Psyllium husk II: effect on the metabolism of apolipoprotein B in African green monkeys. American Journal of Clinical Nutrition 56, 385-393.

Mazur A, Remsey C, Gueux E, Levrat M-A \& Demigne C (1990) Effects of diets rich in fermentable carbohydrates on plasma lipoprotein levels and lipoprotein catabolism in rats. Journal of Nutrition 120, 1037-1045.

National Cholesterol Education Program Expert Panel on Detection, Evaluation, and Treatment of High Blood Cholesterol in Adults (1990) Report of the National Cholesterol Education Program Expert Panel on detection, evaluation and treatment of high blood cholesterol in adults. Archives of Internal Medicine 148, 36-69.

Posadas-Romero C, Tapia-Conyer R \& Lerman-Garber I (1995) Cholesterol levels and prevalence of hypercholesterolemia in a Mexican adult population. Atherosclerosis 118, 275284.

Schneeman BO \& Tinker LF (1995) Dietary fiber. Pediatric Nutrition 42, 825-838.

Shepherd J \& Packard CJ (1996) Dyslipoproteinemia and coronary heart disease. Triglycerides and coronary heart risk. Israeli Journal of Medical Science 32, 345-355.

Sprecher DL, Harris BV \& Goldberg AC (1993) Efficacy of psyllium in reducing serum cholesterol levels in hypercholesterolemic patients on high- or low-fat diets. Annals of Internal Medicine 7, 545-554.

Spiller RC (1994) Pharmacology of dietary fibre. Pharmacology and Therapeutics 62, 407-427.

Turley SC, Daggy B \& Dietschy JM (1994) Psyllium augments the cholesterol lowering action of cholestyramine in hamsters by enhancing sterol loss from the liver. Gastroenterology 1107, 444-452.

Turley SD \& Dietschy JM (1995) Mechanisms of LDL-cholesterol lowering action of psyllium hydrophilic mucilloid in the hamster. Biochimica et Biophysica Acta 1255, 177-184.

Uusitupa MIJ, Ruuskanen E, Makinen E, Laitinen J, Toskala E, Kervinene K \& Kenaniemi A (1992) A controlled study of the effects of beta-glucan-rich oat bran on serum lipids in hypercholesterolemic subjects: relationship to apolipoprotein $\mathrm{E}$ phenotype. Journal of the American College of Nutrition 11, 651-659.

Vidal-Quintanar RL, Hernandez L, Conde K, Vergara-Jimenez M \& Fernandez ML (1997) Lime-treated corn husks lower plasma LDL cholesterol in guinea pigs by altering hepatic cholesterol metabolism. Journal of Nutritional Biochemistry $\mathbf{8}$, 479-486.

Vuorinen-Makkola H, Sinisalo M \& Koivisto VA (1992) Guar gum in insulin-dependent diabetes: effects on glycemic control and serum lipoproteins. American Journal of Clinical Nutrition 56, 1056-1060.

Warnick GR, Benderson J \& Albers JJ (1982) Dextran-sulphate $\mathrm{Mg}^{2+}$ precipitation procedure for quantification of highdensity lipoprotein cholesterol. Clinical Chemistry 28, 13791388 . 
Warnick RS \& Teng LE (1996) Analytical procedures for measurement of the lipid and lipoproteins in cardiovascular risk assessment. In Handbook of Lipids in Human Nutrition, pp. 2135 [GA Spiller, editor]. Boca Raton, FL: CRC Press Inc.
Wyatt CJ, Mendez RO, Triana MA \& Melendez JM (1995) Protein, energy, fat, and mineral composition of diets for lowincome adults in Sonora, Mexico. American Chemical Society 43, 510-515. 